\title{
On Becoming an Engineer: The Essential Role of Lifelong Learning Compe- tencies
}

\section{Jillian Seniuk Cicek, University of Manitoba}

Jillian Seniuk Cicek is a PhD Candidate in Engineering Education in the Department of Biosystems Engineering at the University of Manitoba, in Winnipeg, Canada. She is a research assistant for the Centre for Engineering Professional Practice and Engineering Education in the Faculty of Engineering. Her research areas include outcomes-based teaching and assessment methods and tools, student-cantered instruction (SCI), the Canadian Engineering Accreditation Board (CEAB) graduate attributes and accreditation activities, and engineering students' identities.

\section{Dr. Sandra Ingram, University of Manitoba}

Sandra Ingram, Ph.D., is a SSHRC award-winning scholar and Associate professor in Design Engineering, Associate Chair (NSERC Design Engineering) and adjunct professor in Biosystems Engineering at the University of Manitoba in Winnipeg, Canada. Dr. Ingram is responsible for teaching the engineering communication course in the faculty as well as an integrated approach to communication in the Biosystems Engineering department. Her research interests include professional skills in engineering, internationally educated engineers, co-operative education programs, women in engineering, and post-graduate training of engineers

Dr. Marcia R. Friesen, University of Manitoba 


\title{
On Becoming an Engineer: The Essential Role of Lifelong Learning Competencies
}

\begin{abstract}
Similar to the ABET EC-2000 3a-k learning outcomes, one of the required attributes within the accreditation framework developed by the Canadian Engineering Accreditation Board (CEAB) is lifelong learning. It is a competency defined by CEAB as an ability to identify and to address [students'] own educational needs in a changing world in ways sufficient to maintain their competence and to allow them to contribute to the advancement of knowledge. It is an attribute that is often held up as an exemplar demonstrating the difficulties inherent in assessing the graduate attributes, particularly the ones that reflect the professional or workplace skills of engineers. Some consider lifelong learning an outcome best measured a priori: in other words, it is cogitated as an aptitude that students will best epitomize once they are graduated and working as professional engineers. However, the knowledge, skills, behaviours, attitudes and values that engender lifelong learning are indeed present in our students, and one of the most effective ways to activate and observe this attribute is to engage students in discussions regarding their experiences and perceptions of their learning. This paper presents the findings from a qualitative directed content analysis of two interviews and four focus groups, as 13 student participants discuss their learning experiences within their engineering programs in the Faculty of Engineering at the University of Manitoba, a large research university in Central Canada. Students' lifelong learning aptitudes, which are defined in this study by Deakin Crick Et al.'s seven Dimensions of Learning Power, are evidenced in the data, demonstrating both the capacity of, and the means by which to assess this attribute while students are in our programs. Additionally, we can use students' developing competencies in lifelong learning to improve our own understanding of how students transform into becoming engineers. This paper makes a case for keeping lifelong learning as a required outcome and graduate attribute for our engineering students, and advocates for careful deliberation regarding the definition of lifelong learning, especially in regards to the recently proposed changes to ABET EC-2000 Criteria 3.
\end{abstract}

\section{Introduction and objectives}

In the Faculty of Engineering at the University of Manitoba, a large research university in central Canada with an accredited engineering undergraduate program, two studies were undertaken to explore students' educational experiences and perceptions. One study was designed to be a formative assessment tool for an introductory Thermodynamics course that was restructured using Student Centered Learning methods to explore the instructor's and students' experiences and perceptions in the anticipation of analyzing the data for findings related to student learning outcomes and engagement ${ }^{1,2}$. The second study was devised to investigate fourth year students' perceptions of the Canadian Engineering Accreditation Board (CEAB) Graduate Attribute competencies as developed within their Engineering program ${ }^{3-5}$.

In analyzing the data from both studies for evidence of student learning outcomes and engagement, and student perceptions of the CEAB Graduate Attributes, an unexpected finding emerged: the knowledge, skills, attitudes, behaviours and values that can be attributed to the learning outcome and graduate attribute of lifelong learning were evidenced in the data. Students 
demonstrated meaning making, curiosity, creativity, strategic awareness and resilience while they relayed their experiences and perceptions in regards to both course and program involvements. Additionally, students demonstrated value and appreciation for the opportunity to reflect and voice their opinions on their learning experiences, as well as on their own perceived technical and professional strengths and limitations. Ultimately, through exercising the aptitudes associated with lifelong learning, students exhibited developing self-concepts of what it means to be an engineer.

In this paper, we present the findings from a qualitative directed content analysis of two interviews and four focus groups, as 13 engineering student participants, in their discussions regarding their learning experiences specific to a first year Thermodynamics course, and a Mechanical and Biosystems engineering program, demonstrate the aptitudes for lifelong learning. The analysis is guided by the research question that emerged from the data: What evidence of students' aptitudes for lifelong learning is found when students are encouraged to speak about their learning experiences? The data are analyzed via hypothesis coding that was constructed using the seven Dimensions of Learning Power from Deakin Crick et al.'s (2004) Effective Lifelong Learning Inventory (ELLI) ${ }^{6}$, and the emergent codes of Becoming an engineer and Appreciation for lifelong learning. Through this pilot study, which has serendipitously emerged from these data, we propose to explore both the capacity and the means by which to assess the outcome and attribute of lifelong learning while students are in our programs, as well as the hypothesis that we can use students' developing competencies in lifelong learning to enhance our understanding of how students formulate what it means to become an engineer. This paper makes a case for keeping lifelong learning as a required outcome and graduate attribute for our engineering students for the benefit of both our students and ourselves, in our roles as engineering educators and advocates, and for careful deliberation regarding lifelong learning, especially in regards to the recently proposed changes to ABET EC-2000 Criteria 3.

\section{Background: Lifelong learning}

One of the required attributes within the accreditation framework developed by the Canadian Engineering Accreditation Board (CEAB) is lifelong learning. It is a competency defined by $\mathrm{CEAB}$ as an ability to identify and to address [students'] own educational needs in a changing world in ways sufficient to maintain their competence and to allow them to contribute to the advancement of knowledge ${ }^{7}$. The ABET Criterion $3 \mathrm{a}-\mathrm{k}$ learning outcomes also include an outcome for lifelong learning, although these criterion are under review: i) A recognition of the need for, and an ability to engage in, lifelong learning ${ }^{8}$.

Lifelong learning is an outcome and attribute that is often held up as an exemplar demonstrating the difficulties inherent in assessing graduate attributes and student outcomes, particularly the ones that reflect the professional, or workplace skills of engineers. Some consider lifelong learning an outcome best measured a priori: in other words, it is cogitated as an aptitude that students will best epitomize once they are graduated and working as professional engineers $^{9,10}$. It is difficult, some argue, to measure lifelong learning in an authentic and repeatable way ${ }^{9}$, as what comprises lifelong learning, and how we recognize and quantify it, are challenging to determine ${ }^{11}$. 
The struggle engineering educators have had with lifelong learning in particular seems to have drawn the attention of ABET. Last year, ABET proposed changes to their Criterion 3 outcomes, with the first go-round reducing the 11 outcomes to six, eliminating a number of outcomes, including 3.i., lifelong learning. Reactions to ABET's initial reorganization of Criterion 3 were of alarm, and responses were swift and divided ${ }^{12,13}$. One camp decried the reduction of student outcomes to only ones deemed 'necessary' to engineering, and in particular, rejected the removal of all references to educating engineering students with a focus on developing a broad education, an aptitude for life-long learning, a knowledge of contemporary issues, an understanding and commitment to professional responsibility, and most importantly, developing global and multidisciplinary competencies ${ }^{12,13}$. The opposing camp argued that a reduced list of outcomes would increase program innovation, while at the same time remove outcomes difficult to assess $^{12,13}$.

Since that first reorganization, ABET has proposed a second one, comprised now of seven learning outcomes. Lifelong learning has reappeared: 6. An ability to recognize the ongoing need for additional knowledge and locate, evaluate, integrate, and apply this knowledge appropriately $^{14}$, but with a significant difference. This new definition focuses almost exclusively on the information literacy aspect of lifelong learning, or the skills to seek, manage and use knowledge. It effectively removes any implications that lifelong learning would incorporate or require reflecting on, identifying and characterizing one's self as a learner. As Mourtos (2003) postulated, when ABET first developed EC2000, Criterion 3, the lifelong learning outcome was comprised of two facets that required two different sets of skills: "the 'recognition of the need' requires the skills in the affective domain, while the 'ability to engage' requires the skills in the cognitive domain"15. Litzinger et al. (2005) further characterize the self-directed learner as being characterized by attributes, including "curious/motivated, methodical/disciplined, logical/analytical, reflective/self-aware, flexible, interdependent/interpersonally competent, persistent/responsible, venturesome/creative, confident, independent/self-sufficient," and skills, such as highly developed information seeking and retrieval skills; knowledge about, and skills to engage in the learning process; and skills for evaluating and engaging in critical thinking ${ }^{16}$. $\mathrm{ABET}$, in redefining lifelong learning, arguably to eliminate the difficulties deemed inherent in its assessment, reduced the outcome to skills relegated to the cognitive domain, and removed all references to the affective domain. Ironically, this new standard decreases the likelihood of program innovation in regards to lifelong learning, one of ABET's arguments for the initial reorganization, and impetus behind the original development of EC 2000 Criterion 3: "They [the student outcomes] were intentionally designed to be non-prescriptive, providing academic programs enough latitude so that they have the freedom to innovate" 13 .

Despite the concerns surrounding the semantics, the reintroduction by ABET of the outcome and attribute, lifelong learning, seems to indicate that it is an outcome and attribute considered valuable for engineers and engineering education, and essentially worth the struggle. This attitude was evident in the literature when ABET first proposed lifelong learning as part of Criterion 3, and historically, long before ${ }^{9,15-17}$. Engineering educators argue for the relevance of lifelong learning, some considering it the most important of the professional engineering skills ${ }^{18}$ due to our rapidly changing technological and global societies ${ }^{16,18}$. The necessity for engineers to adapt quickly and creatively to this swiftly moving 'modern knowledge' 21 st century economy ${ }^{17}$ requires the skills and behaviours attributed to lifelong learning. These skills and behaviors need 
to be developed and identified in our students while they are in our engineering education

programs so that when they enter the field, they are well equipped to adapt to this world ${ }^{17-19}$.

\section{Methodology}

This pilot study emerged from data collected in the Faculty of Engineering at the University of Manitoba during two previous studies. Two open-ended interviews and four focus groups were conducted with engineering student participants between July 2013 and March 2015. One study was designed to be a formative assessment tool for an introductory Thermodynamics course that was redesigned using Student Centered Learning methods, to explore the instructor's and students' experiences and perceptions in the anticipation of analyzing the data for findings related to student learning outcomes and engagement ${ }^{1,2}$. The second study was devised to investigate fourth year students' perceptions of the CEAB Graduate Attribute competencies as developed within their Engineering program ${ }^{3-5}$. All interview and focus group transcripts were member-checked to substantiate the data for these previous studies ${ }^{20}$.

Students in the Thermodynamics study were asked to speak about their experiences in the course; teaching strategies that facilitated their learning; their characteristics as a learner (i.e., How do you learn best? What is your preferred style of learning? Do you prefer individual or group work?); and to reflect on any unexpected learning outcomes. One interview $(\mathrm{n}=1)$ and one focus group $(n=2)$ were conducted. For the Graduate Attribute study, students were asked to speak about their time within the program (i.e., most valuable aspects; knowledge, skills and experiences gained; program strengths and weaknesses); their personal views and expectations of the knowledge and skills needed to practice engineering (i.e., role of a P.Eng.; expectations of a P. Eng.) and whether they needed to adjust those expectations; gaps in their education; and graduate attributes, competencies, extra-curricular activities, and the student graduate attribute exit survey. One interview $(n=1)$ and three focus groups were conducted $(n=2 ; n=2 ; n=5)$ (see Table 1).

TABLE 1: Interviews \& Focus Groups Labels

\begin{tabular}{|c|l|c|}
\hline Label & \multicolumn{1}{|c|}{ Description } & $\begin{array}{c}\text { Number of } \\
\text { Participants }\end{array}$ \\
\hline I.1 & Student Interview - Thermodynamics Study, July 2014 & 1 \\
\hline I.2 & Student Interview (Biosystems) - Graduate Attributes Study, May 2014 & 1 \\
\hline FG.1 & Student Focus Group - Thermodynamics Study, July 2013 & 2 \\
\hline FG.2 & Student Focus Group (Mechanical) - Graduate Attributes Study, March 2014 & 2 \\
\hline FG.3 & Student Focus Group (Mechanical) - Graduate Attributes Study, March 2014 & 2 \\
\hline FG.4 & Student Focus Group (Mechanical) - Graduate Attributes Study, March 2015 & 5 \\
\hline
\end{tabular}

In analyzing the data for the original studies, it became evident that students were exercising the competencies characteristic of the outcome and attribute of lifelong learning. This pilot study is an effort to further explore this emergent finding. A qualitative directed content analysis method was chosen, as it would enable a focus on the contextual meaning of the text, and meet the research objective to 'provide knowledge and understanding of the phenomenon under study, ${ }^{21}$, namely students' aptitudes for lifelong learning, a deductive approach suited to the research question and objective of the study ${ }^{22}$. 
Content analysis is defined as 'a research method for the subjective interpretation of the content of the data through the systematic classification process of coding and identifying themes or patterns ${ }^{21}$. As it was hypothesized that the aptitudes for lifelong learning were present in these data, and this hypothesis required testing, the research literature on lifelong learning was investigated for potential theory or theoretical frameworks to guide the study. Deakin Crick et al's (2004) Effective Lifelong Learning Inventory (ELLI) was selected for a number of reasons ${ }^{6}$. Importantly, Deakin Crick et al. (2004) have extensively investigated how to characterize lifelong learning, and write about its many facets ${ }^{6}$. They explore the notion of lifelong learning holistically in its relevance over one's lifetime, as well as in the context of traditional learning, including classroom, formal and informal, and self-directed learning ${ }^{6}$. They position their work within the context of educational research regarding learning, identifying achievement and personal development as the two successful strands of learning ${ }^{6}$. They argue that pedagogical structures are built around achievement, which often marks the end of the learning process, but that personal development is ongoing, and thereby, most accurately aligned with lifelong learning ${ }^{6}$. They developed the seven Dimensions of Learning Power that are characteristic of successful lifelong learning through extensive factor analysis and testing on large school-aged populations $^{6}$. They are: 1. Change and Learning; 2. Meaning Making; 3. Critical Curiosity; 4. Creativity; 5. Learning Relationships; 6. Strategic Awareness; 7. Resilience ${ }^{6}$. In 2007, the ELLI in Higher Education (HE) Project was undertaken, involving 14 universities in the United Kingdom, in which the learning dimensions were shown to be valid for these HE populations ${ }^{23}$. These seven dimensions of learning were adapted as a theoretical framework for this pilot study. Qualitative codebooks ${ }^{24}$ for use with hypothesis coding of the data, a method most often used with content analysis ${ }^{25}$, were subsequently developed.

Two qualitative codebooks were generated: the first an aggregated version with one to three key phrases to describe each learning power as defined by Deakin Crick et al. $(2004)^{6}$. A second, more comprehensive codebook was developed using the same seven categories but extensively defining each, as well as including a list of $3-12$ behaviours illustrating what students can do to exemplify each learning power. For example, for change and learning, students can: Review earlier work and compare with their current assessments etc. in order to recognize their development ${ }^{23}$. This comprehensive codebook was built using The Effective Lifelong Inventory ELLI Staff Guidebook ${ }^{23}$, and was constructed with the objective 'to give explicit definitions, examples and coding rules for each deductive category, determining exactly under what circumstances a text passage can be coded with a category ${ }^{22}$.

The data were coded using both codebooks: first the aggregated version was consulted, and then analysis was verified with the comprehensive codebook. As the process unfolded, key phrases that characteristically defined the categories within the data and that emerged consistently from the data, were taken from the comprehensive codebook and added to the aggregated codebook. In this way, as recommended by Creswell (2014), the preliminary (aggregated) codebook developed and changed based on the findings from the data analysis ${ }^{24}$ (see Table 2 for final codebook.) Additionally, two new categories, i.e., Becoming an engineer and Appreciation for lifelong learning emerged from the data, resulting in the use of a combination of predetermined and emerging terms ${ }^{24}$.

For this paper, one researcher coded the data, using a cycle of pre-coding, preliminary jottings, and hypothesis coding ${ }^{25}$, and validating the accuracy of the findings ${ }^{24}$ through a constant 
comparison cycle with the two codebooks. Two researchers then reviewed the analysis to corroborate its trustworthiness $^{20}$. Plans to expand this work include potential quantitative analysis using frequency counts ${ }^{25}$, and expansion of data analysis using multiple coders ${ }^{24}$.

TABLE 2: Aggregate codebook using Deakin Crick Et al.'s seven Dimensions of Learning Power ${ }^{6}$ and emergent categories

- Circle bullet Indicates preliminary definition

$>$ Arrow bullet Indicates emerging definition

1. Change and Learning (as opposed to stuck \& static)

- The extent to which students see themselves grow as learners

$>$ Take steps to expand their repertoire of learning skills

2. Meaning Making (as opposed to data accumulation)

- Links to prior learning (what they are learning \& what they already know)

$>$ Enjoy seeing things 'fit' together

3. Critical Curiosity (as opposed to passivity)

- Asking questions, digging; not accepting knowledge at face value

$>$ Recognizing that learning is sometimes difficult; enjoy the challenge

$>$ Take ownership of learning

4. Creativity (as opposed to being rule-bound)

- Looking at things in new and different ways

$>$ Actively try different approaches to learning

$>$ Don't worry if stuck on a problem

5. Learning Relationships (as opposed to isolation and/or dependence)

- Working effectively on their own or with others

- Balancing working alone and with others; willingness to seek help

$>$ Helping others

6. Strategic Awareness (as opposed to being robotic)

- Self-aware of own learning; try different approaches; plan learning

$>$ Think about the big picture

$>$ Understand what they are trying to achieve

$>$ Recognize failure can be positive; learn from own and others' mistakes

$>$ Understand the criteria by which they'll be assessed

7. Resilience (as opposed to fragility and dependence)

- Enjoy a challenge; carry on in face of frustration or confusion

$>$ Not frightened to find things difficult

$>$ Understand the climate that helps them learn best

$>$ Be prepared to try new things

Emergent Categories:

$>$ Becoming an engineer

Appreciation for lifelong learning 


\section{Findings}

\subsection{Seven Dimensions of Learning Power: Characteristics of successful lifelong learning}

Preliminary findings reveal that the proposed hypothesis of evidence of behaviours in lifelong learning is confirmed in the data ${ }^{25}$. Participants' perceived learning experiences and subsequent exploration of them could be interpreted through the theoretical framework constructed for this pilot study using Deakin Crick et al.'s (2004) seven Dimensions of Learning Power: 1. Change and learning; 2. Meaning making; 3. Critical curiosity; 4. Creativity; 5. Learning relationships; 6 . Strategic awareness; and 7. Resilience ${ }^{6}$. All seven dimensions were evidenced in every interview and focus group transcript. Although no formal frequency counts have been conducted to date, preliminary quantitative analysis shows that Strategic Awareness was a dominant dimension in the data.

\subsubsection{Change and learning (as opposed to being stuck and static)}

Students recognized that learning can grow and improve over time, and understood that this requires effort. They were willing to take steps to expand their own learning skills, and were able to recognize their learning achievements.

\section{- The extent to which students see themselves grow as learners}

“...it's dependent [students' ability to learn from Capstone project] on your desire to put forward a really honest effort..." (FG 4, student 3 )

"I feel ready to tackle an engineering problem..." (I 2)

"Like our project, I'm rather excited, they're actually going to, they are building it, they're making it better, but they're building it." (FG 4, student 2)

“...as you mature through the program you have an understanding of where you're going to fit in once you graduate." (FG 2, student 2)

"And believe me I always panic, my friends would see that ...I have anxiety every exam, [but] for that term...my friend was like, you're not panicking...yeah [I said]..." (FG 1, student 2)

“...when I first joined the program I didn't really still fully understand what we do... when you started getting to the stress analysis courses... you realize what you're actually doing" (FG 3, student 1)

\section{Take steps to expand their repertoire of learning skills}

“... [that course] really helped [me learn] how to use machines... drilling and assembling a real product, that's really helpful...practical. If I didn't take that course and work with machines there, I wouldn't know how to use [those machines] at all" (FG 4, student 4) 
“...the technical stuff is something unique and I think it's valuable...I can go help my

grandpa on the farm and say, I kind of know how to do this now..." (I 1)

\subsubsection{Meaning making (as opposed to data accumulation)}

Students looked for connections between their prior knowledge and what they were currently learning. They enjoyed identifying those connections and recognizing how new knowledge relates to, or could relate to, what they already knew. They were curious about how their learning fit into the bigger picture and they appreciated learning about what was authentic to them and to their understanding of the engineering profession.

\section{- Links to prior learning (what they are learning and what they already know)}

"Stats...definitely needs to have it more focused towards engineering ...you can do a lot of statistical analysis in T Life Expectancies and even Operational Management. Stats plays a huge role in those." (FG 4, student 3)

“...[operating machines] makes a huge impact on your instinct for practical design. In order to be able to... design something that can be made on a machine, you have to understand how the machine works..." (FG 4, student 1)

“...if you learn to know how to read and interpret codes in one field, it's very easily transferable...bringing in some real world examples would really help with that... something where you can connect the theory to real life." (FG 4, student 2)

“...math is very building and I find with Thermal it was the same thing, if you don't understand the basics, or if you don't understand how to use the tables or how to use the formulas, you don't know how you do the cycles." (FG 1, student 1)

“...whatever job you go into whether it's engineering or not it [communication and design] never will be separate from the rest of your work. So being able to combine it and get used to combining those things at the same time is really helpful..." (I 1)

\section{$>$ Enjoy seeing things 'fit together}

"...I was lucky enough to take Measurement and Controls and then the next month I was working in testing; I was like oh, I'm using all these things I just learned" (FG 4, student 3)

“...it wasn't until Machine Design until we really started talking about physical components of machines, and that's what we're going to be facing once we get to industry." (FG 3, student 1)

“...the chance to apply your class learnings to real life situations and then learn more hands-on stuff ...I think is my most important thing” (FG 2, student 2) 


\subsubsection{Critical curiosity (as opposed to passivity)}

Students questioned what they were learning and tried to understand it, as opposed to accepting given knowledge at face value. They demonstrated their engagement in deep rather than superficial learning, and were interested in discussing it. They took ownership of their learning, and while they recognized that learning could be difficult, they enjoyed the challenge.

\section{- Asking questions, digging; not accepting knowledge at face value}

“...A lot of times in engineering you don't get the chance to work with your hands and see how things can get put together and taken apart. And I think as much as possible we should try and be exposed more to the true mechanical workings of pieces of equipment machinery, that's a big part of mechanical engineering..." (FG 4, student 3 )

“...don't memorize the problem, don't memorize the formula, learn how to derive the formula." (FG 1, student 2)

"I don't have to get an A+ in every single course... (FG 1, student 1) ...I think it's better if you understand the courses..." (FG 1, student 2)

\section{Recognize that learning is sometimes difficult; enjoy the challenge}

“...you need to challenge people to work in teams they're not familiar..." (FG 4, student 1)

"...this question looks kind of challenging but I can break it up, I can deal with each part separately..." (FG 1, student 1)

"Heat Transfer, it's a really challenging course but I really enjoyed it. I find it's quite fast in that there's so much to learn ..." (FG 3, student 1)

\section{Take ownership of learning}

“...where you take a couple of hours of your time to go and see these and it's really useful to see something like that operate... there's many small things that I know I'd love to learn" (FG 4, student 2)

"...[If] I want to do that kind of job I need to do some more training after university." (FG 4, student 4)

"I really like getting to learn the actual skills like when we did welding ...just cause that's something that I never would have been exposed to or kind of forced to do...being able to say like I built this with my hands... that really stands out as something unique and I like to say I did it, I did it." (I 1) 


\subsubsection{Creativity (as opposed to being rule-bound)}

Students showed an ability to try different approaches to learning, rather than tackling learning in the same manner, bound to rules. They were able to look at things in new and different ways, and were not troubled by being stuck on a problem.

\section{- Looking at things in new and different ways}

"...I look at friends and I can tell that they're having trouble....and then that made me think in a different way...” (FG 1, student 1)

"...I liked the idea of engineering... I knew it combined being creative and being able to use some of those more out of the box..." (I 1)

\section{$>$ Actively try different approaches to learning (as opposed to being rule-bound)}

"Because I went so divergent from the actual requirements, I created a flowchart" (FG 4, student 2)

"We're students (chuckle), we just want to break the rules, so yeah I'm going to [choose the incorrect answer] just for fun, we don't mean harm, but it's fun." (I 2)

“...I think a good way to do it was...just to research a lot of different methods that are used in the real world in different applications" (FG 3, student 2)

\section{Don't worry if stuck}

"I enjoy the unknown." (FG 2, student 2)

“...most of the problems, they're the same actually, just different tricks...so when he taught us the strategy then we could go and try all the other [exams] and we know how to do it."

(FG 1, student 2)

\subsubsection{Learning relationships (as opposed to isolation and/or dependence)}

Students were able to recognize when they should work alone, and when they should work as a team. They could identify people who could help them learn; and they recognized the value of working in a team and helping others to learn. They showed the ability to strike a balance between independence and dependence in their learning, rather than being isolated or overly dependent on others.

\section{- Working effectively on their own or with others}

“...we know how to work as a team..." (FG 4, student 2) 
"...you'll learn more if you tell someone what to do and they tell you what to do as well." (FG 1, student 2)

"...you learn to communicate with one another and if you have difficulties in your group you learn to manage those difficulties before you get into the real world." (FG 3, student 1)

- Balancing working alone and with others; willingness to seek help

“...I did what worked for me then when I was stuck I asked my group members.” (I 2)

“....as long as I work on those skills and I know I can do it, I'm confident saying to an employer you know, yeah I forgot all those equations from my textbook but if you show them to me I know exactly how to use them." (I 1)

\section{$>$ Helping others}

"...I majored or specialized in manufacturing so I...show and tell the junior members how to do that..." (FG 4, student 2)

“...the mechanicals [we] are fairly helpful with peers I found; they're more willing to share information with each other. Which can be very beneficial...it's nice to get help from other people when you're struggling." (FG 2, student 1)

"...at the end of the day, we're just human and we, the more open we are, the more we teach people..." (I 2)

\subsubsection{Strategic awareness (as opposed to being mechanical, or passive about learning)}

Students showed the ability to plan their time, think about the big picture, understand what they wanted to achieve, recognize that failure can be positive, learn from their own and others' mistakes, and understand the criteria by which they would be assessed. They showed a great deal of self-awareness.

\section{- Self-aware of own learning; try different approaches; plan learning}

"I' $m$ wondering if there is something that can be done... stuff like workshops and say, this is how you design for screws...just small things like that where they are small things but they're very important things to be learnt..." (FG 4, student 2)

"We make terrible decisions. Myself, I didn't actually know that there was a recommended course schedule until I'd already finished my first year and was part-way into my second." (FG 4, student 2)

"I really liked the Intersession course...I liked how they mixed the tutorials with the lectures and you had the homework...it really enforced what you learnt in the class itself." (FG 1, student 1) 


\section{Think about the big picture}

"It's a huge gap in our education; we don't know how to test." (FG 4, student 2)

“...having something like just a brief paragraph [on the impact on the environment] required on a lot of the design reports, it brings it [impact on the environment] to something real; you have to think about it..." (FG 4, student 2)

"I [have] got to get some experience before I graduate. Otherwise I'm not going to get a job." (FG 3, student 2)

“...even research, I don't care that I didn't get paid, it was experience and it was awesome and it fit perfect in my education..." (I 1)

\section{Understand what they are trying to achieve}

"...I was looking forward to doing that course because the course content was related to what I really wanted to do..." (FG 4, student 1)

"I feel like oh this is why I'm learning this because I would like to know it for this job..." (FG 2, student 1)

“...the reason I didn't take that technical elective is from what I've heard through other people is it's again more theoretical and less application. So I don't feel it would have helped me..." (FG 3, student 1)

\section{Recognize failure can be positive; learn from own and others' mistakes}

"...I know I've seen people hammer away at it [Finite Element Analysis (FEA)] and they get pretty colours but their results are totally invalid because they learnt on their own how to make the colours look interesting but they don't know how to really use the software. And that's actually kind of dangerous too when you think about it because people are leaving university where they've sort of half figured out how to do FEA but they don't know how to do it right..." (FG 4, student 2)

"...my friends they know that what the problem was, they don't know how to read the table, just imagine, they risk, there's one who failed it because... she went through the class until the chapter seven without knowing how to read the table, like how are you going to do that?" (FG 1, student 2)

“...it's okay to make mistakes..." (FG 2, student 1)

“...you learn a lot from mistakes...” (FG 2, student 2) 


\section{Understand the criteria by which they'll be assessed}

"So they'll test you, so if you don't do well that is to show that okay you may not have been as good as you thought you were." (I 2)

\subsubsection{Resilience (as opposed to fragility and dependence)}

Students showed resilience: they carried on learning even when frustrated or confused, and were not frightened to find things difficult. They understood the climate that helped them learn best.

They were prepared to try new things; and they understood that all learners find some things difficult.

\section{- Carry on in face of frustration or confusion}

“...I got six projects and five of them are group projects and five different groups and that's really challenging on the time management to meet up with different groups during the daytime, [but] that really helped me a lot in my time managing." (FG 4, student 4)

"I really worked hard to be in the faculty." (FG 1, student 2)

"...every week we had to do a quick up for two minutes and tell me about something [presentation]... in front of the class and that forces you to suck it up and do it and get used to it." (I 1)

\section{Not frightened to find things difficult}

"I think you have to manage your expectations on what you're actually going to do once you enter the field right, you're not going to be the next greatest thing." (FG 2, student 2)

"I've learned to practice a lot of difficult questions, so I'm more relaxed when I see something more difficult but I see that okay I've done difficult things too so I can tackle this." (I 2)

“...hopefully I get a job soon, within the month would be nice, but...if I'm signing up for a stress job, the hand calculations for designing a truss system, what depth does that require in industry? You know we deal with a small little thing, but that's going to be a big learning curve for me." (FG 4, student 2)

\section{Understand the climate that helps them learn best}

"...that's almost a better way to learn than being taught...throw you in the pool and see if you swim...” (FG 3, student 2) 


\section{$>$ Be prepared to try new things}

“...there's so much more that you could learn that you didn't, so it's kind of you just hope that when you go to the job you'll just pick up the skills there and just kind of hit the ground running..." (FG 3, student 1)

"...getting that hands-on experience because... you know you can do the theoretical... but it's the hands-on stuff you have to be open to learning about" (FG 2, student 1)

\subsection{Becoming an engineer: Students'self concepts}

Through reflecting on their educational experiences, students disclosed developing constructs of what it means to become an engineer. These constructs were revealed in both the junior and senior-level students. This underscores the importance of students being given the opportunity to exercise their lifelong learning skills and aptitudes from the beginning of the program, as their conception of becoming an engineer evolves.

Junior-level students (i.e., first or second year engineering students):

“...our job is to ensure the safety regardless of what field you're in, it's all about the safety of the public. So if you're not approachable and you can't work with the public how are you going to protect the public, I think that's a huge aspect" (I 1)

"I'm in engineering because I like the different ways you can think about stuff, the ways that it teaches you, the ways that the friendships that you build over struggling with the questions, the inside jokes of being able to look at a fire hydrant like a rigid cylinder" (FG 1 , student 1)

\section{Senior-level students (i.e., final year engineering/graduating students):}

“...you have to respect the machinists and respect your trades... having a little bit more of that experience just seeing the depth of what they have to know is very useful in just being an engineer." (FG 4, student 2)

"I don't think as students we're taught enough about how important it is to be a professional faculty and what that means to you and what that means is your responsibilities... a lot of it is in regard to ethics. As a professional you have the ethics code to stand by... Also about understanding your role and the potential for you to do harm to the public and also your role and responsibilities to protect the public" (FG 4, student 3 )

"The impact of engineering on society and environment is extremely important..." (FG 4, student unknown)

"To mitigate the consequences and to basically protect the public and act in a professional code of ethics and follow standards and laws and don't take bribes... Accountability is huge." (FG 3, student 1) 
"...it changed the way I view engineering as a whole... I have a new approach, like every course no matter how difficult it is I can actually tackle it if I really understand what I'm doing and I enjoy what I'm doing" (I 2)

"I think you have to understand that maybe not a fresh green engineer but as you progress in your career that your decisions have significant impact on situations. And I think understanding that [is] important...it's a bit of a pressure and acting professional in those situations, you might have to make a hard decision and there's certain ways to act and conduct yourself as a professional." (FG 2, student 2)

“...when I originally started engineering I kind of figured that after I was going to be done I was going to know all the answers to all these problems, but in a lot of cases I feel like it's more giving you the tools that you will need to figure out how to solve those problems. ...engineers shouldn't do things just because they're going to get a high mark, they do things cause that's, it's an ethics thing, that's what's right or that's what's proper..." (FG 2, student 1)

"...to be an engineer you need to know the laws that govern the natural world... our job is to create technologies that better humanity, but at the same time making sure that those technologies don't hurt us... you have to really be serious about what you're doing because... people's lives are at stake" (FG 3, student 2)

\subsection{Appreciation of lifelong learning: Student values}

Students appreciated, i.e., understood, the concept of lifelong learning and how it applied to them as a learner, (i.e., A recognition of the need for, and an ability to engage in, lifelong learning $^{8}$ ), and appreciated, i.e., valued, the opportunity to engage in lifelong learning through reflecting on their own learning, and their learning experiences. They appreciated i.e., valued that we, as researchers and educators, showed our respect and trust for them by asking them to reflect on their learning and their learning needs. Interestingly, the junior-level students seemed to take the 'ability to engage' in lifelong learning approach in their responses, appreciating the opportunity to identify and/or address their own educational needs, perhaps naturally demonstrating that they were applying their aptitudes for lifelong learning to the future portion of their engineering degree. The senior-level students' comments had a more reflective quality, with the 'recognition of the need' to engage in lifelong learning more pronounced, which again is perhaps natural, as these students are beginning a new phase of their engineering careers.

\section{Appreciated, i.e., understood, the concept of lifelong learning and how it applied to them as a learner (i.e., $A$ recognition of the need for, and an ability to engage in, lifelong learning)}

Senior-level students (i.e., final year engineering/graduating students):

“...the time stuff, it is like a lifelong skill so we need to manage it..." (FG 4, student 4)

“...lifelong learning, I thought it was the most important” (FG 4, student 5) 
"You guys are throwing everything at us, right?! It's lifelong learning." (FG 4, student 5)

"I feel like it's developed a curiosity in myself which is really important for lifelong learning and trying to you know figure things out..." (FG 4, student 3)

"Maybe as engineers your whole idea as an engineer is to be able to stay current and use and implement technology as it progresses." (FG 4, student 3)

\section{Appreciated, i.e., valued, the opportunity to identify and/or address their own} educational needs (i.e., in ways sufficient to maintain their competence and to allow them to contribute to the advancement of knowledge ${ }^{7}$.)

Junior-level students (i.e., first or second year engineering students):

"I do have enough of a foundation that I know how to learn it again in a relatively quick way so if I need it in the field I can go back to the resources that I now have and then apply it again...it's comforting to know that I have that base to go back to... when you think back you're like okay maybe that question will never come into play but the ability to learn this and now having those basic skills will come in handy" (I 1)

"I like dealing with hands on problems and being able to see stuff, I really like, and I guess I'm a complete mix cause I love the analytical with the numbers and just doing that, but then I really like being able to actually see how it applies in the real world and seeing oh this does actually make a difference" (FG 1, student 1)

Appreciated i.e., valued that we, as researchers and educators, showed our respect for, and trust in, them by asking them to reflect on their learning and their learning needs

Senior-level students (i.e., final year engineering/graduating students):

"I didn't know what this focus group was going to be like but I, now that we're here doing it I kind of enjoy this...Like this opportunity just to share whatever you want about the program... I'm really enjoying having the opportunity just to talk about the program with some peers." (FG 2, student 2)

"Thank you very much for having me. It was a pretty good experience...It's good to vent." (FG 3, student 1)

"I learned so much I just want to give back." (I 2)

“...it feels good to talk about it... it was a really good idea cause it's a good way to evaluate us at the end of the program. It's like okay, so basically what did you [I] learn... it took me by surprise already. I don't know, I just, I guess I didn't think I would be asked for my input" (FG 3, student 2) 


\section{Discussion}

The analysis of this qualitative data could be couched in the researchers' subjective interpretation that they bring to this study through their personal culture, history and experiences $^{24}$ : essentially, a philosophical position of the critical importance of the aptitudes inherent in the outcome and attribute of lifelong learning. However, analyzing the data through Deakin Crick et al.'s (2004) seven Dimensions of Learning Power revealed the pervasiveness of the skills and behaviours characteristic of successful lifelong learning ${ }^{6}$. All seven dimensions, i.e., 1. Change and learning; 2. Meaning making; 3. Critical curiosity; 4. Creativity; 5. Learning relationships; 6. Strategic awareness; and 7. Resilience 6 were found in each interview and focus group transcript. This suggests that encouraging students to reflect on their learning experiences and voice their opinions regarding these and their own learning is a viable way for students to demonstrate their aptitudes regarding this outcome and attribute, as well as to demonstrate how it is fostered within their engineering programs. This quantification of lifelong learning is also advocated in research:

Lifelong learning is the attribute that is most difficult to quantify and demonstrate an understanding of, and how it contributes to life as a working professional. Consequently, it is the attribute that students have the most to gain from, as it is a skill that will help them as the world evolves. By introducing reflective mediums into the curriculum, the notion of lifelong learning is quantified, with direct evidence to demonstrate that competency to the Accreditation Board. Encouraging students to dive deeper into their education and examine how they can gather more information and guide them to be better learners will strengthen the concept of lifelong learning. ${ }^{26}$

Having students reflect on their educational experiences enabled them to exhibit their appreciation of lifelong learning as a necessary and valuable skill and behaviour. Interestingly, the junior-level students seemed to take the 'ability to engage' in lifelong learning approach in their responses, applying their aptitude for lifelong learning to the future portion of their engineering degree. The senior-level students' comments had a more reflective quality, with the 'recognition of the need' to engage in lifelong learning more pronounced. It would be noteworthy to further explore the differences between junior and senior level students, as their responses underscore the importance of both domains of lifelong learning, and support the argument that the ABET definition should encompass both. These responses also challenge the concept that lifelong learning is more suited to assessment 'a priori'; markedly, these students exhibit the aptitudes that embody lifelong learning in their junior and senior engineering years.

Furthermore, through students' practice of reflexivity, educators can gain an understanding of how students conceptualize becoming an engineer. Conceptions of becoming an engineer were found in both the junior and senior-level student responses, although they were perhaps developed more concretely in the latter. This finding emphasizes the importance of students being given the opportunity to exercise their lifelong learning skills and aptitudes from the beginning of the program, as they formulate their understandings of what it means to become an engineer. This is valuable information for engineering educators as it reflects what is being communicated through our programs to our students about what it means to be an engineer, and how students intellectualize this information. These data can have great significance in informing 
our decisions regarding program improvement, which is a faculty responsibility and necessary for accreditation, adding another dimension to the argument for fostering lifelong learning competencies in our engineering students.

There are limitations to this study. Applying predetermined codes offers the risk that researchers will 'find what they are looking for ${ }^{24}$. Care was taken to minimize this potential bias by the construction of two codebooks and the constant comparative cycle of analyses that was applied in coding the data. Additionally, clearly demonstrating how the findings fit into the developed lifelong learning framework supports the analyses in this study. Having more than one researcher coding the data, as is proposed in expanding this study, will further minimize this risk. Another potential bias may be found in the sample of participants: students who self-select to participate in an interview or focus group regarding their learning likely have tendencies indicative of lifelong learning. As one student said regarding participants' opinions: “...I guess in that sense it's almost... a positive bias because you want the input from the people who really care about what they learned..." (FG 3, student 2). It would be worthwhile to expand this study to investigate the aptitude for lifelong learning in larger and more randomized samples. Furthermore, as one reviewer of this paper has suggested, the data could be analyzed to determine if the quality or depth of the students' responses differs between the junior and senior level cohorts. This approach has been cursorily considered with these data in this pilot study. However, as there is a pronounced difference in the number of participants in each cohort (the junior cohort had three students, and the senior cohort 10), this type of analysis would be better served in an expanded version of this study.

Despite these limitations, it was the emergent finding of the aptitudes for lifelong learning in these two data sets that was the impetus for this pilot study being conducted, which is an exciting discovery for engineering educators. The authors of this study support careful consideration of the revisions to the ABET Criterion 3 outcome, lifelong learning, as it is an attribute that our students can demonstrate; its assessment provides valuable data for program evaluation and improvement; and it comprises knowledge, skills, behaviours, attitudes and values required for our students' success as $21^{\text {st }}$ century engineers ${ }^{26}$.

\section{Conclusions and Recommendations}

Similar to the ABET EC-2000 3a-k learning outcomes, one of the required graduate attributes within the accreditation framework developed by the Canadian Engineering Accreditation Board (CEAB) is lifelong learning. It is a competency defined by CEAB as an ability to identify and to address [students'] own educational needs in a changing world in ways sufficient to maintain their competence and to allow them to contribute to the advancement of knowledge. It is an attribute that is often held up as an exemplar demonstrating the difficulties inherent in assessing the graduate attributes, particularly the ones that epitomize the professional or workplace skills of engineers. Some consider lifelong learning an outcome best measured once students are graduated and working as professional engineers; however, other engineering educators argue vehemently for its value while students are still engaged in their programs, as it is a competency that will be both necessary and beneficial to new engineering graduates as they enter the field. 
This study in the Faculty of Engineering at the University of Manitoba has demonstrated that the knowledge, skills, behaviours, attitudes and values that engender lifelong learning are indeed present in our engineering students, and while formally assessing this attribute through the curriculum may pose unique challenges to instructors, one effective way to activate and observe this attribute is to engage students in discussions regarding their experiences and perceptions of their learning. This paper makes a case for keeping lifelong learning as a required outcome and graduate attribute for our engineering students, and advocates for careful deliberation regarding the definition of lifelong learning, especially in regards to the behaviours and skills attributed to the affective domain, which may cease to be relevant for programs accredited under ABET if the proposed definition for lifelong learning stands. In this pilot study, students' lifelong learning aptitudes as defined by Deakin Crick et al.'s (2004) seven Dimensions of Learning Power are evidenced in students' interviews and focus group discussions. The findings from this study suggest both the capacity and means by which to assess lifelong learning while students are in our programs. Furthermore, we can use students' developing competencies in lifelong learning to improve our own understanding of how students conceptualize becoming engineers, valuable information to inform engineering program development and improvement, a concern of all engineering education stakeholders. Above all, lifelong learning is an attribute that will equip our students with essential tools for professional practice, growth and success as $21^{\text {st }}$ century engineers. We have a professional responsibility to develop this outcome in our engineering students.

\section{References}

1. Seniuk Cicek, J., Ruth, D., and Ingram, S. 2013. "Thermodynamics is not a spectator sport!”: An exploratory study on incorporating active learning into a first year thermodynamics course. In Proceedings of the Canadian Engineering Education Association Conference (CEEA/ACEG), 7 pp. Montreal, QC. June18-20.

2. Seniuk Cicek, J., Ruth, D., and Ingram, S. 2014. Redesigning the learning experience: One professor's efforts to develop an active and engaging first year thermodynamics course. In Proceedings of the Canadian Engineering Education Association Conference (CEEA/ACEG), 7 pp. Canmore, AB. June 8-11.

3. Seniuk Cicek, J., Labossiere, P., and Mann, D. 2013. Surveying fourth year engineering student perceptions of graduate attribute competencies. In Proceedings of the Canadian Engineering Education Association Conference (CEEA/ACEG), 7 pp. Montreal, QC. June18-20.

4. Seniuk Cicek, J., Labossiere, P., and Ingram, S. 2014. Examining fourth year engineering student perceptions of graduate attribute competencies: Year two. In Proceedings of the Canadian Engineering Education Association Conference (CEEA/ACEG), 9 pp. Canmore, AB. June 8-11.

5. Seniuk Cicek, J., Labossiere, P. and Ingram, S. 2015. Examining fourth year engineering student perceptions of graduate attribute competencies: Year three. In Proceedings of the Canadian Engineering Education Association Conference: Experiential Engineering Education (CEEA/ACEG). Hamilton, ON. May 31- June 3.

6. Deakin Crick, R., Broadfoot, P. and Claxton, G. 2004. Developing an effective lifelong learning inventory: the ELLI project. Assessment in Education: Principles, Policy \& Practice, 11(3), 247-272. http://researchinformation.bristol.ac.uk/en/publications/developing-an-effective-lifelong-learning-inventory-the-elliproject(42b6a66c-636b-4409-8998-0bb71911fdc8).html (2016/01/04). 
7. Engineers Canada. 2014. Accreditation. http://www.engineerscanada.ca/accreditation-resources (2014/04/14)

8. Schachterle, L. 1999. Outcomes assessment and accreditation in US engineering formation. European Journal of Engineering Education, 24(2), 121-131. http://www.tandfonline.com/doi/abs/10.1080/03043799908923547 $(2014 / 04 / 24)$.

9. Shuman, L. J., M. Besterfield-Sacre and J. McGourty. 2005. The ABET "professional skills" - Can they be taught? Can they be assessed? Journal of Engineering Education 94(1): 41-55. http://onlinelibrary.wiley.com/doi/10.1002/j.2168-9830.2005.tb00828.x/abstract (2012/01/12).

10. Jiusto, S. and Di Biasio, D. 2006. Experiential Learning Environments: Do They Prepare Our Students to be Self-Directed, Life-Long Learners? Journal of Engineering Education, 95(3): 195-204.

11. Waters, C. Work in progress - Blackboard tracking, can this be a method of ABET outcome i assessment. 2007. In 37th ASEE/IEEE Frontiers in Education Conference. Milwaukee, WI. October 10-13. http://ieeexplore.ieee.org/xpl/login.jsp?tp=\&arnumber $=4417876 \&$ url $=$ http $\% 3 \mathrm{~A} \% 2 \mathrm{~F} \% 2$ Fieexplore.ieee.org $\% 2$ Fxpls\%2Fabs all.jsp\%3Farnumber\%3D4417876 (2014/06/29).

12. Flaherty, C. 2015. Watered-down gen ed for engineers? Inside Higher Ed. https:/www.insidehighered.com/news/2015/06/26/faculty-members-criticize-proposed-changes-gen-edaccreditation-standards-engineers $(2015 / 10 / 20)$.

13. Rogers, J. 2015. Jamie Rogers, ABET president, explains the reasoning behind proposed changes to Criteria 3 and 5. ABET. http://www.abet.org (2015/09/02).

14. 2016-2017 Criteria for accrediting engineering programs - proposed changes: Proposed revisions to criteria for accrediting engineering programs definitions, general Criterion 3 student outcomes, and general Criterion 5 curriculum. 2015. ABET. http://www.abet.org/news/abet-releases-criteria-proposal-for-public-comment/ $(2015 / 10 / 20)$.

15. Mourtos, N. J. 2003. Defining, teaching and assessing lifelong learning skills. In 33rd ASEE/IEEE Frontiers in Education Conference. Boulder, CO. November 5-8. http://citeseerx.ist.psu.edu/viewdoc/download?doi=10.1.1.501.8223\&rep=rep1\&type=pdf $(2014 / 06 / 29)$.

16. Litzinger, T. A., Wise, J. C. and Lee, S. H. 2005. Self-directed learning readiness among engineering undergraduate students. Journal of Engineering Education, 94(2): 215-221. http://onlinelibrary.wiley.com/doi/10.1002/j.2168-9830.2005.tb00842.x/abstract (2013/05/08).

17. Martinez-Mediano, C. and Lord, S. M. 2012. Lifelong learning competencies program for engineers. International Journal of Engineering Education, 28(1): 130-143.

https://www.researchgate.net/publication/233867546_Lifelong_Learning_Competencies_Program_for_Enginee rs $(2016 / 01 / 29)$.

18. Uziak, J. Position of the final year project in an engineering curriculum. 2015. Global Journal of Engineering Education, 17(3): 113-118. http://www.wiete.com.au/journals/GJEE/Publish/vol17no3/02-Uziak-J.pdf (2016/01/07).

19. Altuger-Genc, G. and Chassapis, C. 2011. Fostering lifelong learning in a capstone design environment: An implementation assessment. In 41st ASEE/IEEE Frontiers in Education Conference. Rapid City, SD. October $12-15$.

http://ieeexplore.ieee.org/xpl/login.jsp?tp=\&arnumber $=6142883 \&$ url $=$ http $\% 3 \mathrm{~A} \% 2 \mathrm{~F} \% 2 \mathrm{Fieexplore.iee.}$. org $\% 2$ Fxpls\%2Fabs_all.jsp\%3Farnumber\%3D6142883 (2014/06/29).

20. Leyden, J.A., B. M. Moskal and M. Pavelich. 2004. Qualitative methods used in the assessment of engineering education. Journal of Engineering Education, 93(1): 65-72. 
21. Hsieh, H-F. and Shannon, S.E. 2005. Three approaches to qualitative content analysis. Qualitative Health Research, 15(9): 1277-1288. http://qhr.sagepub.com/content/15/9/1277.short?rss=1\&ssource=mfc $(2016 / 01 / 29)$.

22. Mayring, P. 2000. Qualitative content analysis. Forum Qualitative Sozialforschung / Forum: Qualitative Social Research, 1(2): Art. 20. http://www.qualitative-research.net/index.php/fqs/article/view/1089/2385\%3E $(2016 / 01 / 29)$.

23. Thompson, J., Harding, J. and Williamson, K. 2009. The Effective Lifelong Learning Inventory ELLI: Staff Guidebook. Dispositions to Stay. Northumbria University. 2009-2010. https://www.northumbria.ac.uk/static/5007/sasspdf/LLlearn guide.pdf (2016/01/04).

24. Creswell, J. W. 2014. Research design: Qualitative, quantitative, and mixed methods approaches, $4^{\text {th }}$ ed. L.A., CA: Sage.

25. Saldana, J. 2009. The coding manual for qualitative researchers. L.A., CA: Sage.

26. Middaugh, Erin. McMaster University: Validation of Reflection. Faculty of Engineering, McMaster University. http://fwi.mcmaster.ca/wp-content/uploads/2015/04/validation-reflection-Final-Report.pdf. (January 4, 2016). 